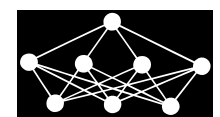

\title{
A COMPARATIVE APPROACH OF NEURAL NETWORK AND REGRESSION ANALYSIS IN VERY SHORT-TERM WIND SPEED PREDICTION
}

\author{
S.K. Jha* J. Bilalovikj
}

\begin{abstract}
The accurate estimation of very short-term wind speed is essential for planning, management, and distribution of wind power produced by any installed wind turbine at a power plant. This study is based on very short-term wind characteristics and meteorological data measured from the wind farm at Bogdanci, in the Former Yugoslav Republic of Macedonia (FYROM) in between May-September 2015. Moreover, the study focuses on the comparative analysis of conventional polynomial based regression analysis and artificial neural network (ANN) methods for very short-term wind speed prediction at the interval of 10 min using four types of wind directions, and three atmospheric parameters. Polynomial regression analysis results in the maximum accuracy $\left(\mathrm{R}^{2}=0.71\right)$ in the prediction of wind speed rotation mean (WSRM) using the wind direction base mean (WDBM) and temperature. The ANN method achieves the best efficiency $\left(\mathrm{R}^{2}=0.97\right)$ in the prediction of WSRM using four types of wind directions and three atmospheric parameters. The ANN performs better than the conventional regression analysis in the prediction of each of the target wind speeds.
\end{abstract}

Key words: regression analysis, artificial neural networks, wind speed estimation, wind energy

Received: November 14, 2017

Revised and accepted: October 16, 2019

DOI: $10.14311 / N N W .2019 .29 .018$

\section{Introduction}

The world demand for electric power is increasing day by day. The use of unsustainable resources, like coal, petroleum, and nuclear materials, etc. in electric power production is costly and one of the factors liable for the climatic and environmental changes $[1,2]$. One of the feasible solutions for clean energy production is to exploit renewable energy sources, like wind energy [3,4] considerably. The research

\footnotetext{
* Sunil Kr. Jha - Corresponding author; Department for Management of Science and Technology Development, Ton Duc Thang University, Ho Chi Minh City, Vietnam; Faculty of Applied Sciences, Ton Duc Thang University, Ho Chi Minh City, Vietnam, E-mail: drsuniljha@tdtu.edu.vn,

${ }^{\dagger}$ Jasmin Bilalovikj; Faculty of Computer Science and Engineering, University of Information Science and Technology "St. Paul the Apostle", Ohrid 6000, Former Yugoslav Republic of Macedonia (FYROM)
} 
and development in the past few decades in electric power production using the wind have been summarized in some review studies [5-10]. More specific details are described in brief about the wind energy assets [5], existing technical knowledge [6], problem-solving processes [7], storage systems [8], strategies [9], and effect on the environment [10], etc. The prediction of wind speed is vital for the estimation of power production and accordingly in scheduling, storage, and distribution. The wind speed is affected by several parameters, including wind characteristics and meteorological factors. Consequently, it is necessary to take account of these factors in wind speed prediction modeling. According to the duration of measurement (years to seconds), wind speed is estimated on long-term [11-14], mediumterm [15,16], short-term [17-40], and very short-term [41-44] basis by using numerical weather prediction models [17], probabilistic, statistical and evolutionary approaches [18-21], artificial neural network (ANN) methods [22-28], the combination of ANN with other methods [28-32], and ANN-based hybrid approaches [33-40], etc. Long-term wind speed estimation is useful in the planning and further process improvement of a wind farm. ANN method is usually used in the long-term wind speed estimation such as the recurrent neural network [11,12] (mean absolute error $(\mathrm{MSE})=1.95$ and root mean square error $(\mathrm{RMSE})=2.67$, respectively), Gaussian mixture copula model (GMCM)-Gaussian process regression (GPR) approach (a minimum value of RMSE $0.06 \mathrm{mph}$ compared to other methods), and ANN method [14] (a minimum mean average error $(\mathrm{MAE})=0.17-0.38$ ). The indexed semi-Markov method has been used in wind speed prediction at long-term, medium-term, and short-term scales [15]. In another study [16], a hybrid method based on a combination of support vector regression, seasonal index adjustment, and Elman recurrent neural network has been developed for the medium-term wind speed prediction (40-41\% improvement in mean absolute percentage error (MAPE)).

Short-term wind speed prediction has better control over the scheduling of power systems compared to long-term and medium-term wind speed predictions. Numerous research reports are available in the literature based on short-term [17-40] and very short-term [41-44] wind speed prediction using statistical and ANN methods [18-40]. ANN methods have been widely used in short-term wind speed prediction; mainly because of the irregular variation in the short-term measurements can be controlled efficiently [22-40]. A few recent applications of ANN methods in short-term wind speed prediction are as follows: back-propagation ANN $(\mathrm{MAE}=0.0016-0.0399)$ [22], abductive network $(\mathrm{MAE}=0.85)$ [23], and feed-forward back-propagation ANN trained with the Levenberg-Marquardt (LM) algorithm (MAPE 4.55\%) [24]. Moreover, the performance of the ANN method in short-term wind speed prediction has been evaluated [25-28], as the performance comparison of back-propagation $(R M S E=1.25)$, radial basis $(\mathrm{RMSE}=1.12)$, and adaptive linear element ANN methods in hourly wind speed prediction [25], a comparative analysis of regression analysis and ANN methods (RMSE $=2.10 \mathrm{~m} / \mathrm{s}$ ) [26], a comparative study of linear, non-linear and back-propagation ANN methods $(\mathrm{RMSE}=0.2)[27]$, and a comprehensive performance analysis of auto-regressive moving average (ARMA), five types of ANN methods and adaptive neuro-fuzzy inference (ANFIS) model, in which ANN methods have less computation time, therefore, it is better for the online application, though the ANFIS model performs 
better than some of the ANN methods [28]. The combination of ANN with other methods also improves the wind speed prediction efficiency [28-33], like the minimum value of the normalized absolute average error of ANFIS method [28] and the minimum value of mean square error $(\mathrm{MSE})=1.85$ ) of fuzzy ARTMAP than ANN method [29], the minimum value of MAPE $=3 \%$ of the ANFIS model [30], the improved performance of the combination of Bayesian combination algorithm and three ANN models [31], and a combination of wavelet transform (WT) and ANN method (the minimum value of MAPE $=6.97 \%$ )) than the ARIMA, ANN and persistence methods [32]. In some recent study, several hybrid models by using ANN methods have been developed [33-40], such as the best performance of wavelet packet-ANN hybrid model than the wavelet packet-BFGS, wavelet packetARIMA-BFGS, ANFIS, and PM methods [33], a hybrid of mesoscale model and ANN (ten neurons in the hidden layer, the minimum value of $\mathrm{MAE}=1.46$ ) [34], a hybrid of ANN and empirical mode decomposition (EMD) (the minimum value of $\mathrm{MAE}=1.13)$ [35], WT, seasonal adjustment method and radial basis function neural network $(\mathrm{RBFNN})$ based hybrid model $(\mathrm{MAPE}=0.23-0.28)[36]$, a hybrid of EMD, mind evolutionary algorithm and ANN, EMD, genetic algorithm and ANN $(\mathrm{MAPE}=66.96 \%-80.32 \%)$ [37], a hybrid of WT, EMD, and Elman neural networks (MAPE $=2.21 \%$ ) [38], AdaBoost and ANN methods based hybrid methods (the minimum RMSE $=2.58$ ) [39], and a hybrid of WT, ANN and multi-resolution analysis $(\mathrm{RMSE}=0.76)[40]$.

The better performance of the ANN method independently, and in combination, in a hybrid model is obvious from the results of past studies [17-40]. Also, specific meteorological parameters (air temperature, air pressure, relative humidity, and rainfall, etc.), and wind characteristics have been used independently or in a combination of inputs of the ANN method in the short-term prediction of standard wind speed. Besides, the standard wind speed, there are some other types, like rotation mean, hub mean, tip low mean, and base mean wind speeds to measure in the wind turbine. The earlier wind speeds affect the generated wind power; therefore, they should be included in wind power modeling by using some artificial intelligence methods, like ANN. The present study is based on modeling of earlier types of wind speeds measured at a wind farm. Specifically, the back-propagation ANN method has been used in wind speeds modeling and its performance is compared using the polynomial regression analysis method. Furthermore, the combination of all measured wind characteristics and atmospheric parameters have been used as the inputs of ANN method and combinations of two of them (one of the wind characteristics and one atmospheric information) having maximum values of the coefficient of correlation have been used in the regression analysis for the prediction of very short-term wind speeds at the interval of $10 \mathrm{~min}$. The monthly data in the prediction of wind speed have been used. Experimental measurements of a few days of each of the months have been used in the training of BPNN and measurements of the rest of the day of a similar month have been used in the validation. The short-term (at the interval of $10 \mathrm{~min}$ ) prediction of average wind speed can be used to design a real-time wind speed simulator. Further, the trained model can be used to develop a real-time wind power system. The online forecast of wind speed and the wind power at wind part can be obtained in less time using the monthly trained BPNN model. The instantaneous wind speed prediction is used in error correction in wind power production and distribution. 


\section{Experimental measurements}

All the experimental measurements have been accomplished at the wind farm in Bogdanci, Former Yugoslav Republic of Macedonia (FYROM). The experimental measurements contain four types of wind speeds, including (a) wind speed rotation mean (WSRM), (b) wind speed hub mean (WSHM), (c) wind speed tip low mean (WSTLM), and (d) wind speed base mean (WSBM); four types of wind directions, including (a) wind direction rotation mean (WDRM), (b) wind direction hub mean (WDHM), (c) wind direction tip low mean (WDTLM), and (d) wind direction base mean (WDBM); and three atmospheric information, including (a) air temperature, (b) air pressure, and (c) relative humidity. The location of the wind farm is between the latitude of $41^{\circ} 20^{\prime} 31^{\prime \prime} \mathrm{N}-41^{\circ} 12^{\prime} 11^{\prime \prime} \mathrm{N}$, and longitude of $22^{\circ} 57^{\prime} 54^{\prime \prime} \mathrm{E}-22^{\circ} 34^{\prime} 32^{\prime \prime} \mathrm{E}$. The Bogdanci area of FYROM has an average wind spend of about $5.5 \mathrm{mph}$. The Siemens wind turbines (SWT-2.3-93) have been installed at the wind park. Each of the wind turbines of capacity $2.3 \mathrm{MW}$ contains a three-bladed rotor (diameter $93 \mathrm{~m}$ ) and fiberglass blades. Wind speeds and directions, and meteorological parameters have been measured using wind direction vanes (NRG 200P), Anemometers (NRG 40, P2546A), temperature sensors (NRG $110 \mathrm{~S})$, pressure and humidity sensors installed in different parts of the turbine. The supervisory control and data acquisition (SCADA) has been used to record wind characteristics and meteorological parameters. The average value of measured meteorological information and wind characteristics at the interval of $10 \mathrm{~m}$ for five months (May-September 2015) has been used in further analysis. Fig. 1 demonstrates the variation of four wind speeds measured in June 2015. Furthermore, other statistical measures of wind characteristics and atmospheric factors are summarized in Tab. I.

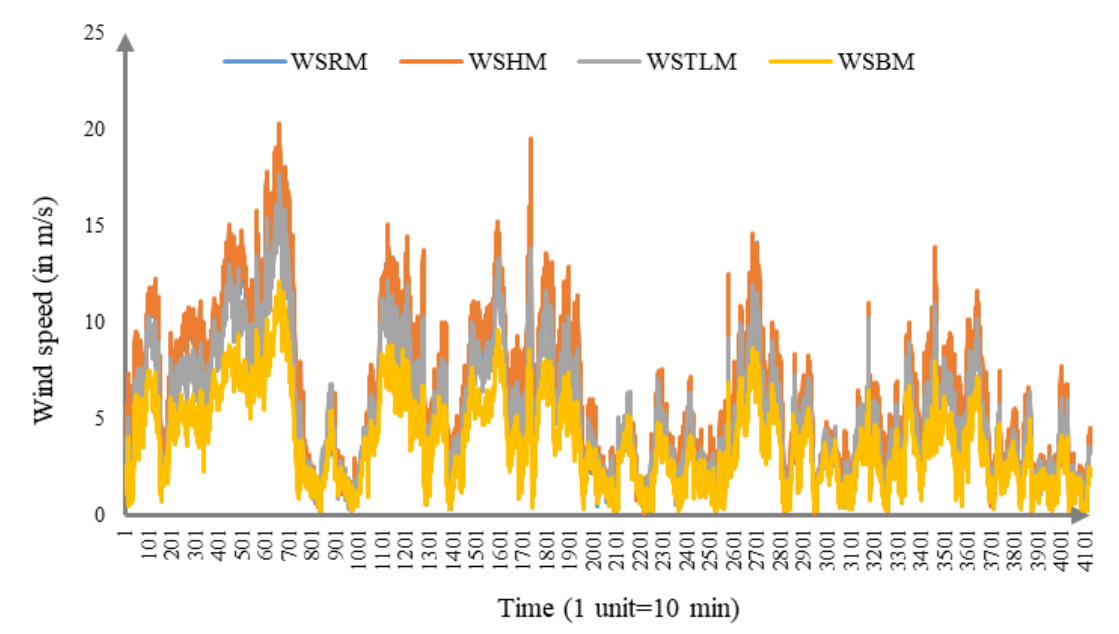

Fig. 1 The variation of wind speed measured at the interval of 10 min in June 2015. 
Jha S.K., Bilalovikj J.: A comparative approach of neural network and...

\begin{tabular}{|c|c|c|c|c|c|}
\hline Month & Measurement & Minimum & Maximum & Mean & Standard deviation \\
\hline \multirow{11}{*}{ 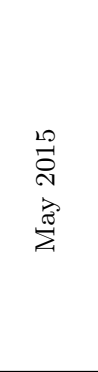 } & WSRM $[\mathrm{m} / \mathrm{s}]$ & 0.25 & 18.62 & 5.66 & 4.02 \\
\hline & WSHM $[\mathrm{m} / \mathrm{s}]$ & 0.23 & 50.54 & 7.82 & 9.26 \\
\hline & WSTLM $[\mathrm{m} / \mathrm{s}]$ & 0.33 & 16.84 & 5.06 & 3.35 \\
\hline & WSBM $[\mathrm{m} / \mathrm{s}]$ & 0.23 & 11.76 & 3.64 & 2.41 \\
\hline & WDRM [degrees] & 2.30 & 358.95 & 247.00 & 87.34 \\
\hline & WDHM [degrees] & 0.79 & 359.77 & 218.30 & 98.58 \\
\hline & WDTLM [degrees] & 2.11 & 359.42 & 246.50 & 87.61 \\
\hline & WDBM [degrees] & 0.63 & 359.44 & 245.40 & 88.11 \\
\hline & Air temperature $\left[{ }^{\circ} \mathrm{C}\right]$ & 10.08 & 26.57 & 18.68 & 3.69 \\
\hline & Air pressure $[\mathrm{hPa}]$ & 959.60 & 973.26 & 966.10 & 3.44 \\
\hline & Relative humidity [\%] & 18.95 & 89.12 & 55.48 & 12.16 \\
\hline \multirow{11}{*}{ 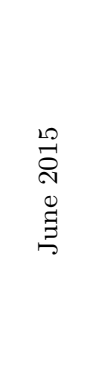 } & WSRM $[\mathrm{m} / \mathrm{s}]$ & 0.23 & 20.04 & 6.00 & 3.91 \\
\hline & WSHM $[\mathrm{m} / \mathrm{s}]$ & 0.09 & 20.32 & 6.25 & 3.96 \\
\hline & WSTLM [m/s] & 0.23 & 17.62 & 5.20 & 3.21 \\
\hline & WSBM $[\mathrm{m} / \mathrm{s}]$ & 0.23 & 12.10 & 3.77 & 2.32 \\
\hline & WDRM [degrees] & 0.43 & 359.88 & 260.57 & 90.65 \\
\hline & WDHM [degrees] & 0.17 & 359.77 & 257.48 & 88.36 \\
\hline & WDTLM [degrees] & 0.27 & 359.73 & 261.50 & 88.50 \\
\hline & WDBM [degrees] & 0.07 & 359.76 & 263.45 & 85.32 \\
\hline & Air temperature $\left[{ }^{\circ} \mathrm{C}\right]$ & 12.11 & 31.61 & 20.03 & 3.96 \\
\hline & Air pressure $[\mathrm{hPa}]$ & 960.70 & 975.97 & 968.96 & 3.42 \\
\hline & Relative humidity [\%] & 24.96 & 92.54 & 55.21 & 14.89 \\
\hline \multirow{11}{*}{ 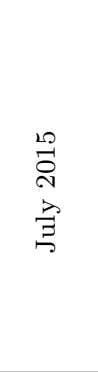 } & WSRM $[\mathrm{m} / \mathrm{s}]$ & 0.33 & 18.02 & 5.24 & 3.55 \\
\hline & WSHM $[\mathrm{m} / \mathrm{s}]$ & 0.23 & 18.31 & 5.52 & 3.62 \\
\hline & WSTLM [m/s] & 0.24 & 16.44 & 4.68 & 2.92 \\
\hline & WSBM $[\mathrm{m} / \mathrm{s}]$ & 0.23 & 11.73 & 3.44 & 2.11 \\
\hline & WDRM [degrees] & 0.06 & 359.85 & 228.87 & 93.84 \\
\hline & WDHM [degrees] & 0.17 & 359.80 & 225.50 & 92.78 \\
\hline & WDTLM [degrees] & 0.03 & 359.99 & 231.11 & 92.07 \\
\hline & WDBM [degrees] & 0.32 & 359.25 & 233.79 & 89.43 \\
\hline & Air temperature $\left[{ }^{\circ} \mathrm{C}\right]$ & 16.65 & 34.88 & 25.18 & 4.12 \\
\hline & Air pressure $[\mathrm{hPa}]$ & 960.30 & 977.45 & 968.61 & 4.150 \\
\hline & Relative humidity [\%] & 19.61 & 90.65 & 45.56 & 13.66 \\
\hline \multirow{11}{*}{ 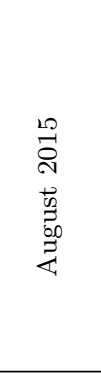 } & WSRM $[\mathrm{m} / \mathrm{s}]$ & 0.23 & 14.46 & 4.18 & 2.52 \\
\hline & WSHM $[\mathrm{m} / \mathrm{s}]$ & 0.13 & 14.61 & 4.48 & 2.61 \\
\hline & WSTLM $[\mathrm{m} / \mathrm{s}]$ & 0.23 & 12.43 & 3.78 & 2.09 \\
\hline & WSBM $[\mathrm{m} / \mathrm{s}]$ & 0.23 & 9.33 & 2.80 & 1.61 \\
\hline & WDRM [degrees] & 0.21 & 360.00 & 220.95 & 96.15 \\
\hline & WDHM [degrees] & 0.03 & 359.93 & 218.91 & 94.73 \\
\hline & WDTLM [degrees] & 0.12 & 359.92 & 222.68 & 93.22 \\
\hline & WDBM [degrees] & 0.20 & 359.95 & 224.93 & 89.49 \\
\hline & Air temperature $\left[{ }^{\circ} \mathrm{C}\right]$ & 14.64 & 33.01 & 24.52 & 3.85 \\
\hline & Air pressure $[\mathrm{hPa}]$ & 962.50 & 977.40 & 969.14 & 3.21 \\
\hline & Relative humidity [\%] & 15.53 & 92.10 & 48.73 & 16.84 \\
\hline \multirow{11}{*}{ 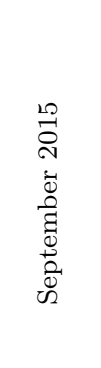 } & WSRM $[\mathrm{m} / \mathrm{s}]$ & 0.22 & 18.66 & 5.48 & 4.14 \\
\hline & WSHM $[\mathrm{m} / \mathrm{s}]$ & 0.08 & 18.52 & 5.72 & 4.12 \\
\hline & WSTLM $[\mathrm{m} / \mathrm{s}]$ & 0.23 & 16.20 & 4.91 & 3.48 \\
\hline & WSBM $[\mathrm{m} / \mathrm{s}]$ & 0.23 & 11.84 & 3.56 & 2.49 \\
\hline & WDRM [degrees] & 1.44 & 359.58 & 233.49 & 89.90 \\
\hline & WDHM [degrees] & 0.08 & 359.87 & 228.85 & 89.21 \\
\hline & WDTLM [degrees] & 0.81 & 359.41 & 234.97 & 87.56 \\
\hline & WDBM [degrees] & 0.10 & 359.97 & 233.09 & 86.80 \\
\hline & Air temperature $\left[{ }^{\circ} \mathrm{C}\right]$ & 11.25 & 33.70 & 20.43 & 5.09 \\
\hline & Air pressure $[\mathrm{hPa}]$ & 961.80 & 974.97 & 968.84 & 2.95 \\
\hline & Relative humidity [\%] & 11.56 & 93.44 & 62.62 & 20.82 \\
\hline
\end{tabular}

Tab. I The monthly statistics of wind characteristics and atmospheric parameters from May-September 2015. 


\section{Analysis and results}

\subsection{Data preprocessing}

The wind characteristics and meteorological data have some random missing values for some days of each of the month, due to instrument failure or operational maintenance on the wind turbine. The preprocessing step of data analysis includes the filtering of missing values of the experimental measurements. Several approaches for controlling of missing data is available in the literature such as deletion, imputation, and maximum likelihood, etc. [45], though, in the present analysis, the deletion approach was selected to reduce further computation. The measurement of WSHM, and WDHM have missing values for 15 days in May 2015, while measurement of WSRM, WSTLM, WSBM, WDRM, WDTLM, WDBM, temperature, pressure, and relative humidity have missing values for seven days, three days, eight days, and six days in July-September 2015, respectively. All the measurements for the missing days have been filtered for each of the months and rest were used for further analysis with the regression and ANN methods. Even by using the conventional deletion methods, sufficient data are available for the wind speed modeling in each of the months. The month of May has a maximum number of missing data, rests of the months have missing data for a few days.

\subsection{Regression analysis}

Correlation values among different wind speeds and their affecting factors have been computed in order to decide the two best inputs (one from the wind direction and another from the atmospheric condition) in the regression analysis. In May, August, and September 2015, WDBM and temperature have the maximum correlation with different types of wind speeds, hence selected for the regression analysis, while in June 2015, WDBM and pressure, and in July 2015, WDRM and temperature have been selected in the prediction of four types of wind speeds due to a maximum value of the correlation. The polynomial regression analysis using two selected inputs with different values of the degree has experimented in MATLAB. Polynomials with two and three degrees result in the best performance in the prediction of different wind speeds. The complete measurements of each of the months have been used in the Polynomial regression model fitting. Analysis results are summarized in Tab. II Four best outcomes of regression analysis in wind speed prediction are shown in Fig. 2. One wind direction and one atmospheric factor (which have higher values of correlation coefficient whether positive or negative) have been selected as inputs in the prediction of wind speed using the regression analysis. For instance, WDBM and air temperature have maximum values of correlation with the wind speeds in May 2015, therefore selected as inputs to regression analysis. The obtained values of the coefficient of determination $\left(\mathrm{R}^{2}\right)$ are summarized in Tab. II, which indicates the best estimation result in the prediction of WSRM $\left(\mathrm{R}^{2}=0.71\right)$. The visual demonstration is shown in Fig. 2(a). Eq. 1 represents the related regression relation.

$$
\mathrm{WSRM}=a+b \times T+c \times \mathrm{WDBM}+d \times T^{2}+e \times T \times W D B M+f \times \mathrm{WDBM}^{2}
$$



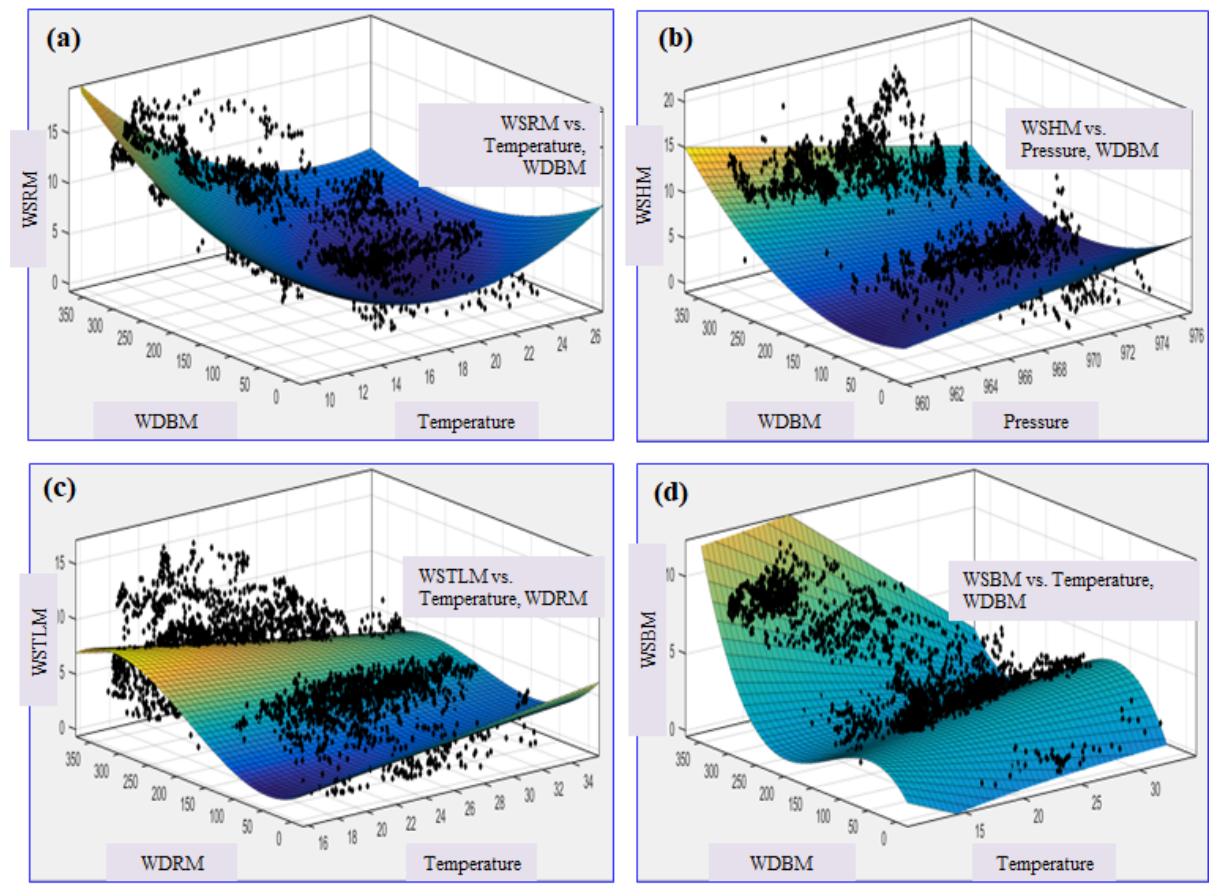

Fig. 2 Polynomial regression analysis results in the prediction of (a)WSRM using temperature and WDBM, (b) WSHM using pressure and WDBM, (c) WSTLM using temperature and WDRM, and (d) WSBM using temperature and WDBM.

where $T$ is air temperature, $a=25.52, b=-2.35, c=0.02, d=0.06, e=$ -0.002 , and $f=-0.00008$. The lower value of $d$, $e$, and $f$ denotes negligible contribution of the second power in the prediction of the WSRM, hence the first power of WDBM, and the air temperature has the main contribution. The WDBM and air pressure have a maximum correlation with the wind speeds in June 2015, consequently, selected as inputs for regression analysis. The outcomes indicate the best prediction of the WSRM, and WSHM $\left(\mathrm{R}^{2}=0.43\right)$. Fig. 2(b) represents the estimation outcomes of the WSHM. The regression expression is represented in Eq. 2.

$$
\mathrm{WSHM}=a+b \times P+c \times \mathrm{WDBM}+d \times P \times \mathrm{WDBM}+e \times \mathrm{WDBM}^{2},
$$

where $P$ is air pressure, $a=-225.6, b=0.24, c=1.74, d=-0.002$, and $e=$ 0.0001 . The lower value of $d$ and $e$ denotes insignificant influence of the second power of dependent variable in the prediction of the WSHM. The WDRM and air temperature have a maximum correlation with the wind speeds in July 2015, consequently, selected as inputs of regression analysis. The outcomes indicate the best prediction of WSRM $\left(\mathrm{R}^{2}=0.47\right)$. Though, in order to demonstrate a different wind speed than the previous case, the estimation outcome of the WSTLM is shown in Fig. 2(c). The related regression expression is represented in Eq. 3. 
Neural Network World 5/2019, 285-300

\begin{tabular}{cccc}
\hline Month & Target & Inputs & $\mathrm{R}^{2}$ \\
\hline \multirow{4}{*}{ May 2015 } & WSRM & & 0.71 \\
& WSHM & WDBM, Air temperature & 0.08 \\
& WSTLM & 0.67 \\
& WSBM & & 0.63 \\
\hline \multirow{5}{*}{ June 2015 } & WSRM & & 0.43 \\
& WSHM & WDBM, Air pressure & 0.43 \\
& WSTLM & & 0.35 \\
& WSBM & & 0.34 \\
\hline \multirow{5}{*}{ July 2015 } & WSRM & & 0.47 \\
& WSHM & WDRM, Air temperature & 0.46 \\
& WSTLM & & 0.37 \\
& WSBM & & 0.32 \\
\hline & WSRM & & 0.43 \\
August 2015 & WSHM & WDBM, Air temperature & 0.41 \\
& WSTLM & & 0.32 \\
& WSBM & & 0.32 \\
\hline \multirow{5}{*}{ September 2015 } & WSRM & & 0.71 \\
& WSHM & WDBM, Air temperature & 0.71 \\
& WSTLM & & 0.65 \\
& WSBM & & 0.63 \\
\hline
\end{tabular}

Tab. II The monthly statistics of wind characteristics and atmospheric parameters from May-September 2015.

$$
\begin{aligned}
\mathrm{WSTLM}= & a+b \times T+c \times \mathrm{WDRM}+d \times T \times \mathrm{WDRM}+e \times \mathrm{WDRM}^{2}+ \\
& +f \times T \times \mathrm{WDRM}^{2}+g \times \mathrm{WDRM}^{3},
\end{aligned}
$$

where $a=-1.19, b=0.17, c=-0.007, d=-0.0015, e=0.0004, f=7.42 \times$ $10^{-7}$, and $g=-7.43 \times 10^{-7}$. The lower value of $c, d, e, f$, and $g$ means minor influence of the second and third power of dependent variable in the prediction of the WSTLM. The WDRM and air temperature have a maximum correlation with the wind speeds in August and September 2015, consequently, selected as inputs to regression analysis. The outcomes indicate the best prediction of WSHM $\left(\mathrm{R}^{2}=0.47\right)$ in August and WSRM and WSHM $\left(\mathrm{R}^{2}=0.71\right)$ in September 2015. Fig. 2(d) represents the estimation outcomes of the WSBM in September. Eq. 4 represents the related mathematical expression.

$$
\begin{aligned}
\mathrm{WSBM}= & a+b \times T+c \times \mathrm{WDBM}+d \times T \times \mathrm{WDBM}+e \times \mathrm{WDBM}^{2}+ \\
& +f \times T \times \mathrm{WDBM}^{2}+g \times \mathrm{WDBM}^{3},
\end{aligned}
$$

where $a=4.72, b=-0.27, c=-0.0085, d=-0.0046, e=-0.00033, f=$ $-1.49 \times 10^{-5}$, and $g=1.31 \times 10^{-6}$. The lower value of $c, d, e, f$, and $g$ means 
Jha S.K., Bilalovikj J.: A comparative approach of neural network and...

the negligible effect of the second and third power of dependent variable in the prediction of the WSRM. Thus, the best performance of regression analysis was achieved for the prediction of WSRM in the month of May and September 2015 using WDBM, and air temperature, while using the same inputs in the month of May for the prediction of WSHM has a minimum value of the coefficient of determination.

\subsection{Artificial neural network analysis}

Four types of wind speeds have a high correlation; therefore, each of them was predicted using the ANN method. The feed-forward back-propagation neural network (BPNN) has been implemented in MATLAB for the wind speed prediction. The Schematic representation of the BPNN is shown in Fig. 3. The mathematical details of BPNN method can be seen in Ref. [46,47]. The BPNN has seven neurons in the input layer, one neuron in the output layer, while the number of neurons in the hidden layer has been optimized to obtain the maximum value of the coefficient of determination $\left(\mathrm{R}^{2}\right)$. The maximum value of $\mathrm{R}^{2}$ has been obtained for the fifty neurons in the hidden layer. Due to the fast convergence characteristics, the Levenberg-Marquardt method was used in the training of BPNN method. The $70 \%$ of total measurements have been used in the training of BPNN, while the rest $30 \%$ have been used in validation and test ( $15 \%$ for each), randomly for each of the months, e.g. in May 2015, out of total 2367 measurements, 1657, 355, and 355 measurements have been used in training, validation, and test, respectively. Though due to a different number of missing measurements for each of the month size of training, validation, and test subsets vary.

The four types of measured wind speeds have been predicted using the four wind directions and three atmospheric factors as inputs of BPNN. Therefore, a total of 20 simulations have been designed in the prediction of four target wind

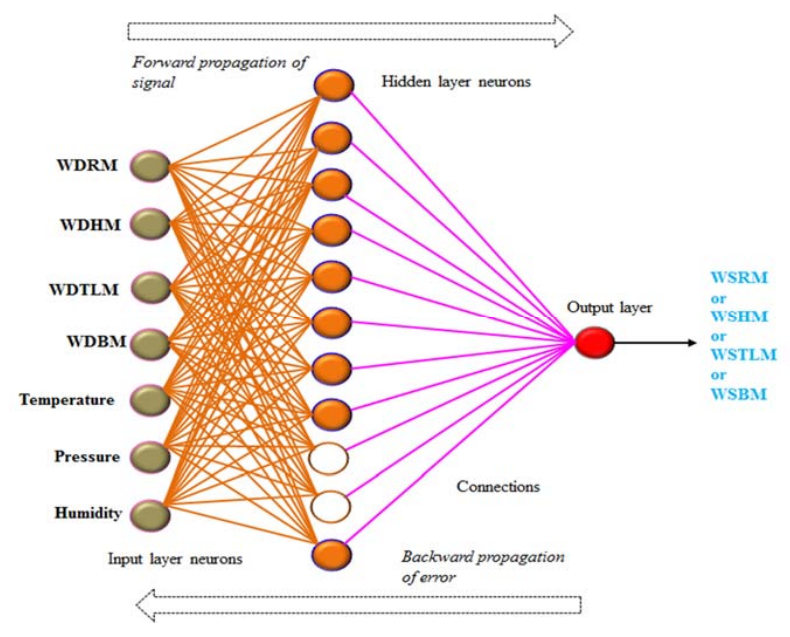

Fig. 3 The schematic representation of feed-forward back-propagation neural network. (BPNN) used in the analysis. 
speeds of five months. A tenfold cross-validation method has been implemented in order to reduce the over fitting of the BPNN model. Tab. III summarizes BPNN analysis results. The visual representation of the best BPNN prediction results is shown in Fig. 4, Fig. 5, Fig. 6, and Fig. 7.

\begin{tabular}{clcccc}
\hline \multirow{2}{*}{ Month } & \multirow{2}{*}{ Target } & \multicolumn{3}{c}{ Coefficient of determination $\left(\mathrm{R}^{2}\right)$} & \\
& Training data & Test data & Validation data & $\mathrm{R}^{2}$ \\
\hline \multirow{3}{*}{ May 2015 } & 0.98 & 0.95 & 0.95 & 0.97 \\
& WSRMM & 0.82 & 0.63 & 0.72 & 0.78 \\
& WSTLM & 0.97 & 0.95 & 0.94 & 0.96 \\
& WSBM & 0.95 & 0.94 & 0.94 & 0.94 \\
\hline \multirow{5}{*}{ June 2015 } & WSRM & 0.90 & 0.82 & 0.8 & 0.87 \\
& WSHM & 0.87 & 0.79 & 0.84 & 0.85 \\
& WSTLM & 0.87 & 0.80 & 0.79 & 0.85 \\
& WSBM & 0.85 & 0.83 & 0.79 & 0.84 \\
\hline \multirow{5}{*}{ July 2015 } & WSRM & 0.92 & 0.88 & 0.88 & 0.91 \\
& WSHM & 0.91 & 0.91 & 0.89 & 0.91 \\
& WSTLM & 0.92 & 0.89 & 0.91 & 0.91 \\
& WSBM & 0.87 & 0.86 & 0.85 & 0.87 \\
\hline \multirow{2}{*}{ August 2015 } & WSRM & 0.86 & 0.81 & 0.83 & 0.85 \\
& WSHM & 0.86 & 0.82 & 0.79 & 0.84 \\
& WSTLM & 0.85 & 0.83 & 0.81 & 0.84 \\
& WSBM & 0.89 & 0.82 & 0.82 & 0.87 \\
\hline & WSRM & 0.98 & 0.96 & 0.97 & 0.97 \\
& WSHM & 0.96 & 0.94 & 0.95 & 0.95 \\
& WSTLM & 0.96 & 0.93 & 0.95 & 0.95 \\
& WSBM & 0.96 & 0.93 & 0.94 & 0.95 \\
\hline
\end{tabular}

Tab. III A summary of BPNN analysis results. Input: WDRM, WDHM, WDTLM, WDBM, Air temperature, Air pressure, Relative humidity.

\section{Discussion}

The variation of four wind speeds Fig. 1 and their quantitative characteristics in Tab. I represent the maximum significance of WSHM and the minimum worth of WSBM in wind power production (since the wind power is proportional to the cube power of wind speed). Though, the maximum value of standard deviation for WSHM and the minimum value for WSBM signifies the maximum dispersion and noise for earlier wind speed. Comparing the measurement of four wind directions, WDBM has a minimum value of dispersion while WDRM has a maximum value of dispersion. Among three atmospheric factors, air pressure has a minimum value of variance while the relative humidity has a maximum value of variance. The correlation coefficient values for five months of measurements denote the degree 
Jha S.K., Bilalovikj J.: A comparative approach of neural network and...
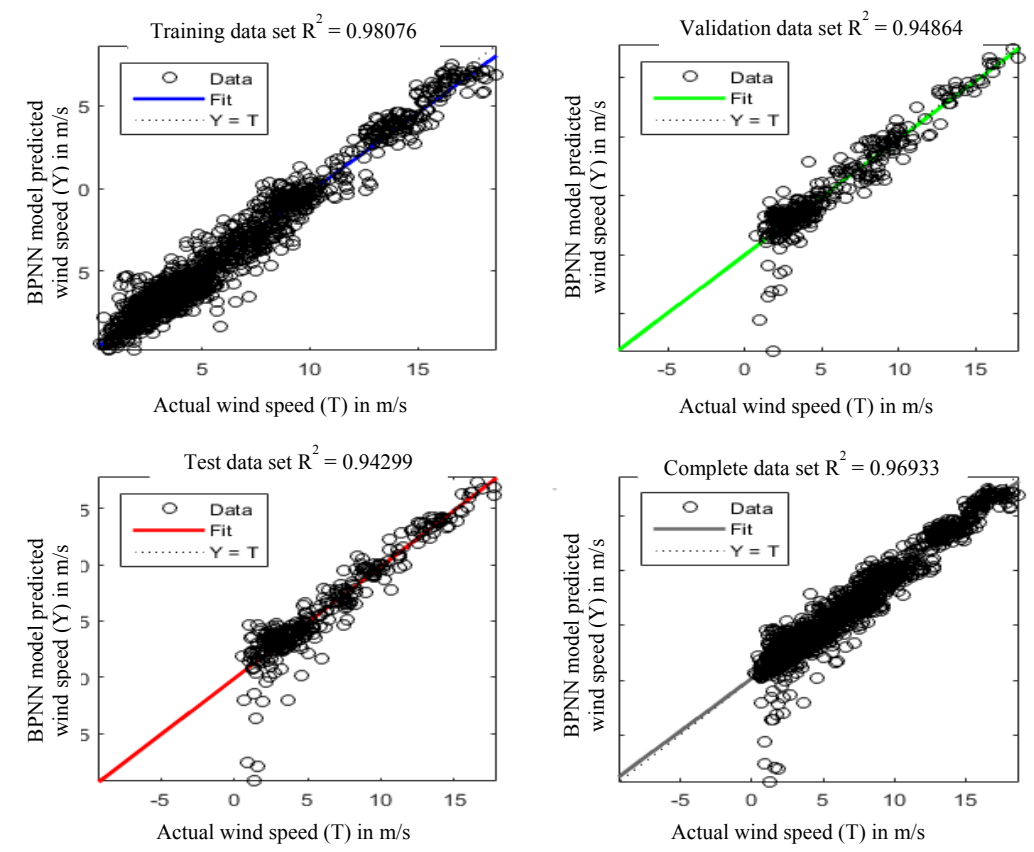

Fig. 4 The BPNN analysis results in the prediction of WSRM using four wind directions and three atmospheric factors as inputs in May 2015.
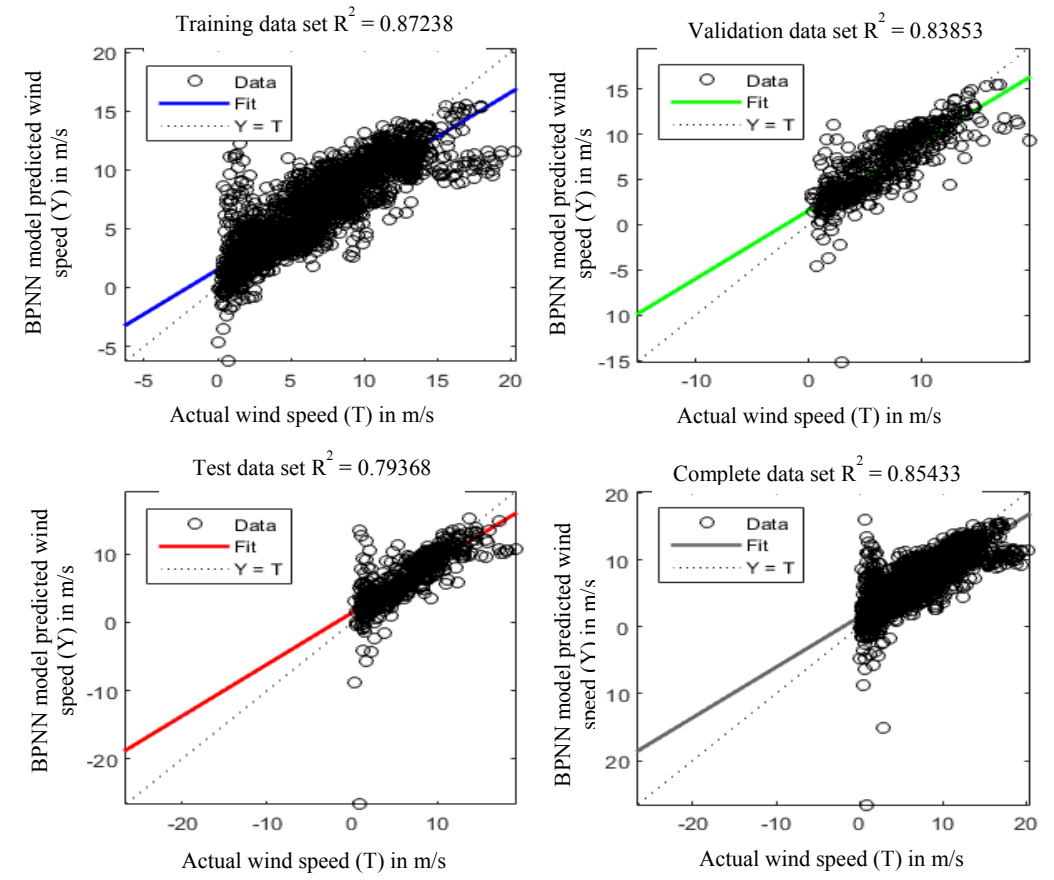

Fig. 5 The BPNN analysis results in the prediction of WSHM using four wind directions and three atmospheric factors as inputs in June 2015. 

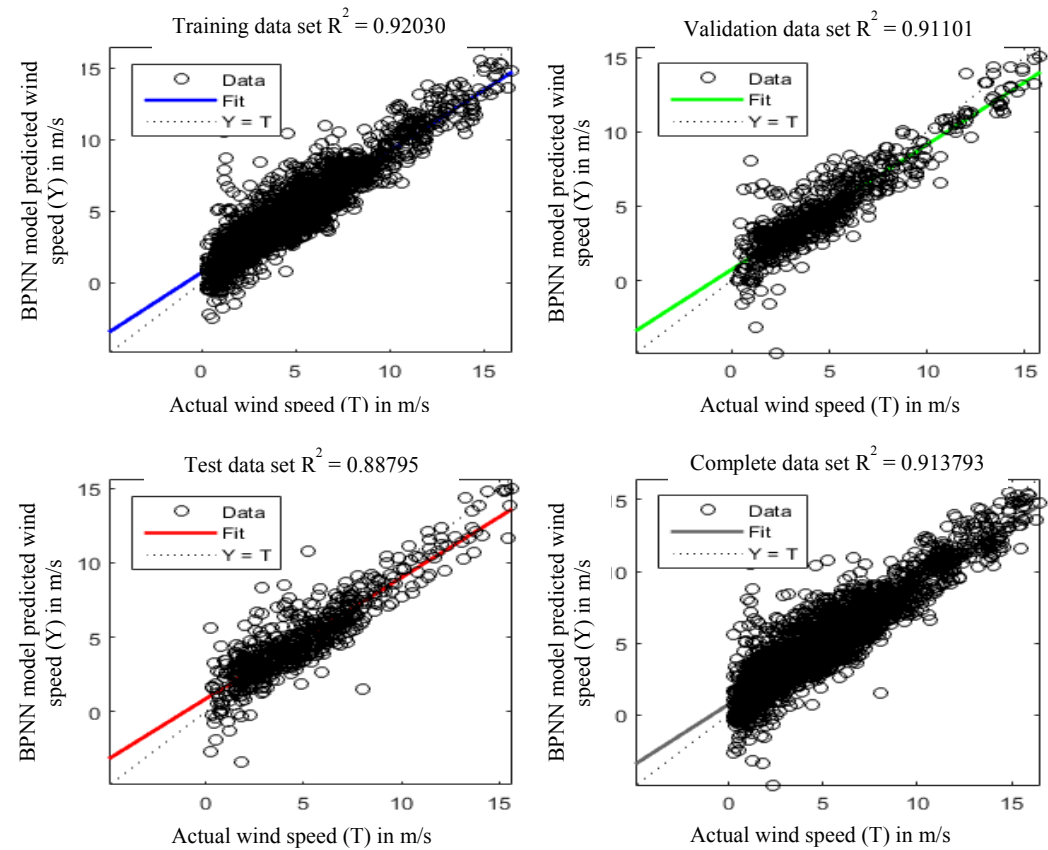

Fig. 6 The BPNN analysis results in the prediction of WSHTM using four wind directions and three atmospheric factors as inputs in July 2015.
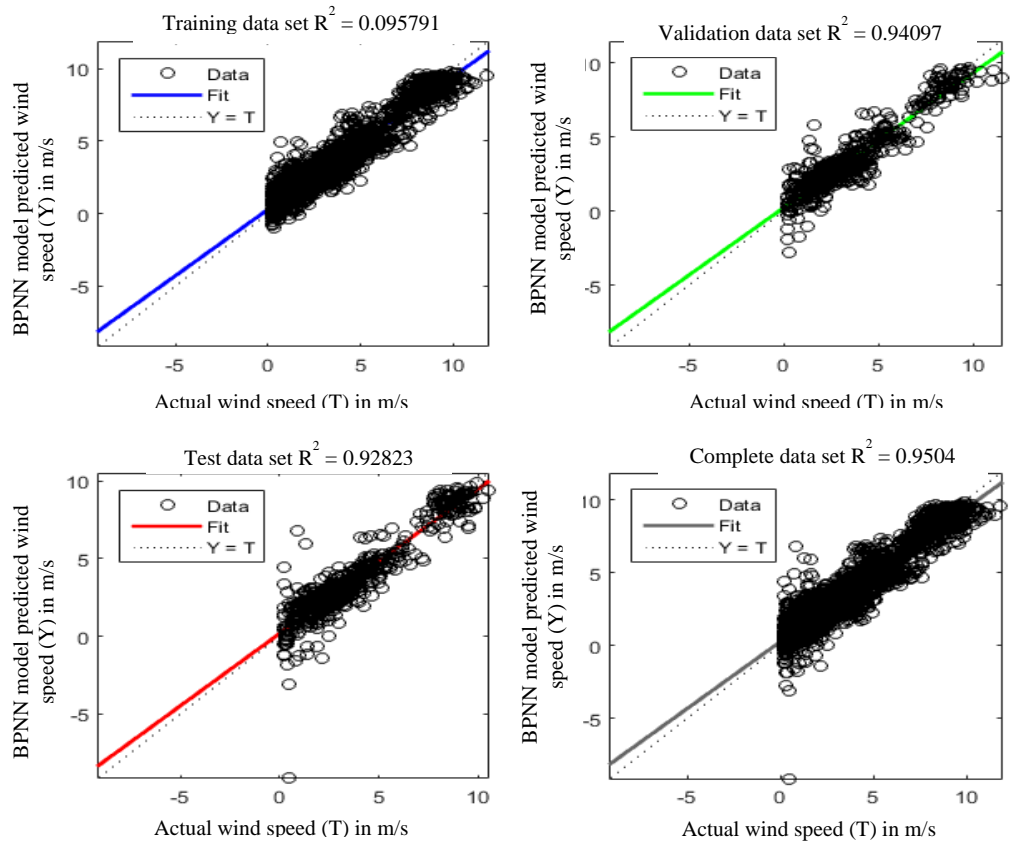

Fig. 7 The BPNN analysis results in the prediction of WSBM using four wind directions and three atmospheric factors as inputs in September 2015. 
Jha S.K., Bilalovikj J.: A comparative approach of neural network and...

of linear association of different wind speeds and affecting factors, including four wind directions, and three atmospheric factors. Each of the wind speed exhibits a high correlation except WSHM in May 2015. The high correlation values were observed among the wind directions. The wind directions have an average value of correlation with wind speeds.

The atmospheric factors have low values of correlation with wind speeds and wind directions. Especially, the temperature has negative correlation with wind speeds for each month of measurements which signify low wind speed at high temperature. From the quantitative results of wind speed prediction using BPNN analysis of the measurements in May-September 2015 in Tab. III, it is apparent that the best performance has been achieved in the estimation of WSRM using all the four wind directions and three atmospheric parameters $\left(\mathrm{R}^{2}=0.97\right)$, while the minimum prediction efficiency $\left(\mathrm{R}^{2}=0.78\right)$ was achieved for the prediction of WSHM in May 2015. The visual representation of BPNN outcomes in the prediction of WSHM for May 2015 is shown in Fig. 4 which shows the best performance of BPNN with training, test, validation, and complete data sets $\left(\mathrm{R}^{2}=0.95-0.98\right)$. Fig. 5 represents BPNN analysis outcomes for the prediction of WSHM in June $2015\left(\mathrm{R}^{2}=0.79-0.87\right)$. The predicted outcomes of WSTLM in July using BPNN are shown in Fig. $6\left(\mathrm{R}^{2}=0.89-0.92\right)$. Fig. 7 exhibits predicted outcome of WSBM using $\operatorname{BPNN}\left(\mathrm{R}^{2}=0.93-0.96\right)$ in September. Consequently, the visual representation in Fig. 4, Fig. 5, Fig. 6, and Fig. 7 of BPNN analysis outcomes for different wind speed prediction and quantitative analysis outcomes in Tab. III demonstrates the superior performance of the BPNN over the regression analysis. Also, combining numerous affecting factors of wind speed modeling with BPNN is simpler and effective than the regression analysis. This is the first kind of study based on the modeling of wind turbine data of FYROM. Consequently, the direct assessment of present results from the previous studies is not feasible. Though some related studies in wind speed prediction are as follows: in [26], improved performance of ANN method compared to regression analysis in terms of RMSE is presented by using only wind direction, in a similar study [27], the maximum value of coefficient of determination was achieved by using the BPNN method and selecting the best set of parameters from air temperature, air pressure, relative humidity, and rainfall by using the regression analysis, while in the present study, the maximum value was achieved by including wind directions in the set of input parameters. The present study is based on the modeling of local wind turbine data, though it addresses a novel way of modeling wind speeds by including several types of wind directions and significant atmospheric factor in a single BPNN method which results in a satisfactory performance $\left(\mathrm{R}^{2}=0.98\right)$. Besides, different kinds of short-term wind speed have been predicted successfully.

\section{Conclusion}

In the present study, different types of wind speeds, wind directions, and atmospheric data, have been measured at the Bogdanci Power Plant in the FYROM for the period of May-September 2015. The average wind speeds have been predicted for each month of measurement at the interval of $10 \mathrm{~min}$ using regression analysis, and BPNN methods. The BPNN method performs better than the regression 


\section{Neural Network World 5/2019, 285-300}

analysis for each type of wind speeds and each month of measurements. The best performance of BPNN has been achieved for the prediction of the WSRM.

\section{References}

[1] GOLLOP F.M., ROBERTS M.J. Environmental regulations and productivity growth: The case of fossil-fueled electric power generation. The Journal of Political Economy. 1983, pp. 654-674, doi: 10.1086/261170.

[2] FRANKL P., NOWAK S., GUTSCHNER M., GNOS S., RINKE T. Technology roadmap: solar photovoltaic energy. International Energy Association. 2010.

[3] TURNER J.A. A realizable renewable energy future. Science 1999, 285, pp. 687-689, doi: 10. 1126/science. 285.5428 .687$.

[4] SORENSEN B. Renewable Energy: Physics Engineering Environmental Impacts Economics ES Planning, $4^{\text {th }}$ ed. Amsterdam: Elsevier, 2011.

[5] SESTO E. Wind energy in the world: reality and prospects. Renew. Energ. 1999, 16, pp. 888-893, doi: 10.1016/S0960-1481(98) \{00298-5\}.

[6] ACKERMANN T., SÖDER L. Wind energy technology and current status: a review. Renew. Sust. Energ. Rev. 2000, 4, pp. 315-374, doi: 10.1016/S1364-0321(00)00004-6.

[7] HASAN N.S., HASSAN M.Y., MAJID M.S., RAHMAN H.A. Review of storage schemes for wind energy systems. Renew. Sust. Energ. Rev. 2010, 14, pp.1744-1762, doi: 10.1016/j. rser.2012.12.028.

[8] LU B., LI Y., WU X., YANG Z. A review of recent advances in wind turbine condition monitoring and fault diagnosis. In: Proceedings of the IEEE Power Electronics and Mechanics in Wind Applications, Lincoln, NE, USA. IEEE, 2009, pp. 1-7, doi: 10.1109/PEMWA. 2009. 5208325.

[9] SAIDUR R, ISLAM M.R., RAHIM N.A., SOLANGI K.H. A review on global wind energy policy. Renew. Sust. Energ. Rev. 2010, 14, pp. 1744-1762, doi: 10.1016/j.rser.2010.03.007.

[10] LEUNG D.Y.C, YANG Y. Wind energy development and its environmental impact: a review. Renew. Sust. Energ. Rev. 2012, 16, pp. 1031-1039, doi: 10.1016/j.rser.2011.09.024.

[11] BARBOUNIS T.G., THEOCHARIS J.B. Locally recurrent neural networks for long-term wind speed and power prediction. Neurocomputing. 2006, 69, pp. 466-496, doi: 10.1016/j. neucom.2005.02.003.

[12] CARTA J.A., VELÁZQUEZ S. A new probabilistic method to estimate the long-term wind speed characteristics at a potential wind energy conversion site. Energy. 2011, 36, pp. 26712685, doi: $10.1016 / j$.energy.2011.02.008.

[13] YU J., KUILIN C., JUNICHI M., MUDASSIR M.R. A Gaussian mixture copula model based localized Gaussian process regression approach for long-term wind speed prediction. Energy. 2013, 61, pp. 673-686, doi: 10.1016/j.energy.2013.09.01.

[14] AZAD H.B., MEKHILEF S., GANAPATHY V.G. Long-term wind speed forecasting and general pattern recognition using neural networks. IEEE Trans. Sustain. Energy. 2014, 5, pp. 546-553, doi: 10.1109/TSTE. 2014.2300150.

[15] D'AMICO G., PETRONI F., PRATTICO F. Wind speed and energy forecasting at different time scales: a nonparametric approach. Physica A: Statistical Mechanics and its Applications. 2014, 406, pp. 59-66, doi: 10.1016/j.physa.2014.03.034.

[16] WANG J., QIN S., ZHOU Q., JIANG H. Medium-term wind speeds forecasting utilizing hybrid models for three different sites in Xinjiang, China. Renew. Energ. 2015, 76, pp. 91101, doi: 10.1016/j.renene.2014.11.011.

[17] CASSOLA F, BURLANDO M. Wind speed and wind energy forecast through Kalman filtering of numerical weather prediction model output. Applied Energy. 2012, 99, pp. 154-166, doi: $10.1016 / j$. apenergy. 2012.03.054. 
Jha S.K., Bilalovikj J.: A comparative approach of neural network and...

[18] RIAHY G.H., ABEDI M. Short term wind speed forecasting for wind turbine applications using linear prediction method. Renew. Energ. 2008, 33, pp. 35-41, doi: 10.1016/j.renene. 2007.01 .014

[19] ORTIZ-GARCÍA E.G., SALCEDO-SANZ S., PÉREZ-BELLIDO A.M., GASCÓNMORENO J., PORTILLA-FIGUERAS J.A., PRIETO L. Short-term wind speed prediction in wind farms based on banks of support vector machines. Wind Energy. 2011, 14, pp. 193-207, doi: 10.1002/we.411.

[20] SALCEDO-SANZ S., ORTIZ-GARCıE.G., PÉREZ-BELlidO A.M., PORTILLAFIGUERAS A., PRIETO L. Short term wind speed prediction based on evolutionary support vector regression algorithms. Expert Syst. Appl. 2011, 38, pp. 4052-4057, doi: 10.1016/j. eswa.2010.09.067.

[21] CHEN K., YU J. Short-term wind speed prediction using an unscented Kalman filter based state-space support vector regression approach. Applied Energy. 2014, 113, pp. 690-705, doi: $10.1016 / j$. apenergy $\cdot 2013.08 .025$.

[22] CADENAS E., RIVERA W. Short term wind speed forecasting in La Venta, Oaxaca, México, using artificial neural networks. Renew. Energ. 2009, 34, pp. 274-278, doi: 10.1016/j. renene.2008.03.014.

[23] ABDEL-AAL R.E., ELHADIDY M.A., SHAAHID S.M. Modeling and forecasting the mean hourly wind speed time series using GMDH-based abductive networks. Renew. Energ. 2009, 34, pp. 1686-1699, doi: 10.1016/j.renene.2009.01.001.

[24] RAMASAMY P., CHANDEL S.S., YADAV A.K. Wind speed prediction in the mountainous region of India using an artificial neural network model. Renew. Energ. 2015, 80, pp. 338-347, doi: $10.1016 / j$.renene.2015.02.034.

[25] LI G., SHI J. On comparing three artificial neural networks for wind speed forecasting. Applied Energy. 2010, 87, pp. 2313-2320, doi: 10.1016/j. apenergy.2009.12.013.

[26] KULKARNI M.A., PATIL S., RAMA G.V., SEN P.N. Wind speed prediction using statistical regression and neural network. J. Earth Syst. Sci. 2008, 117, pp. 457-463, doi: 10.1007/ s12040-008-0045-7.

[27] BILGILI M., SAHIN B. Comparative analysis of regression and artificial neural network models for wind speed prediction. Meteorol. Atmos. Phys. 2010, 109, pp. 61-72, doi: 10. 1007/s00703-010-0093-9.

[28] DE GIORGi M.G., FICARELla A., TARANTINO M. Error analysis of short term wind power prediction models. Applied Energy. 2011, 88(4), pp. 1298-1311, doi: 10.1016/j. apenergy .2010.10.035.

[29] HAQUE A.U., MENG J. Short-term wind speed forecasting based on fuzzy ARTMAP. Int. J. Green Energ. 2011, 8, pp. 65-80, doi: 10.1080/15435075.2010.529784.

[30] MOHANDES M., REHMAN S., RAHMAN S.M. Estimation of wind speed profile using adaptive neuro-fuzzy inference system (ANFIS). Applied Energy. 2011, 88, pp. 4024-4032, doi: 10.1016/j. apenergy . 2011.04.015.

[31] LI G., SHI J., ZHOU J. Bayesian adaptive combination of short-term wind speed forecasts from neural network models. Renew. Energ. 2011, 36, pp. 352-359, doi: 10.1016/j.renene. 2010.06.049.

[32] CATALãO J.P.S., POUSINHO H.M.I., MENDES V.M.F. Short-term wind power forecasting in Portugal by neural networks and wavelet transform. Renew. Energ. 2011, 36, pp. 12451251, doi: $10.1016 / j$.renene.2010.09.016.

[33] LIU H., TIAN H.Q., PAN D.F., LI Y.F. Forecasting models for wind speed using wavelet, wavelet packet, time series and artificial neural networks. Applied Energy. 2013, 107, pp. 191-208, doi: 10.1016/j . apenergy . 2013.02.002.

[34] SALCEDO-SANZ S., PÉREZ-BELLIDO A.M., ORTIZ-GARCÍA E.G., PORTILlAFIGUERAS A., PRIETO L., PAREDES D. Hybridizing the fifth generation mesoscale model with artificial neural networks for short-term wind speed prediction. Renew. Energ. 2009, 34, pp. 1451-1457, doi: 10.1016/j.renene.2008.10.017. 


\section{Neural Network World 5/2019, 285-300}

[35] LIU H., CHEN C., TIAN H.Q., LI Y.F. A hybrid model for wind speed prediction using empirical mode decomposition and artificial neural networks. Renew. Energ. 2012, 48, pp. 545-556, doi: 10.1016/j.renene.2012.06.012.

[36] ZHANG W., WANG J., WANG J., ZHAO Z., TIAN M. Short-term wind speed forecasting based on a hybrid model. Appl. Soft Comput. 2013, 13, pp. 3225-3233, doi: 10.1016/j . asoc. 2013.02.016.

[37] LIU H., TIAN X., LIANG X., LI Y. New wind speed forecasting approaches using fast ensemble empirical model decomposition, genetic algorithm, Mind Evolutionary Algorithm and Artificial Neural Networks. Renew. Energ. 2015, 83, pp. 1066-1075, doi: 10.1016/j. renene.2015.06.004.

[38] LIU H., TIAN X., LIANG X., LI Y., Wind speed forecasting approach using secondary decomposition algorithm and Elman neural networks. Applied Energy. 2015. 157, pp. 183194, doi: 10.1016/j. apenergy . 2015.08.014.

[39] LIU H., TIAN H., LI Y., ZHANG L. Comparison of four Adaboost algorithm based artificial neural networks in wind speed predictions. Energy Convers. Manage. 2015, 92, pp. 67-81, doi: $10.1016 / \mathrm{j}$. enconman.2014.12.053.

[40] Doucoure B., AgBossou K., CARDEnAS A. Time series prediction using artificial wavelet neural network and multi-resolution analysis: application to wind speed data. Renew. Energ. 2016, 92, pp. 202-211, doi: 10.1016/j.renene.2016.02.003.

[41] KANI S.A.P, ARDEHALI M.M. Very short-term wind speed prediction: A new artificial neural network-Markov chain model. Energy Convers. Manage. 2011, 52, pp. 738-745, doi: $10.1016 / j$.enconman.2010.07.053.

[42] BLONBOU R. Very short-term wind power forecasting with neural networks and adaptive Bayesian learning. Renew. Energ. 2011, 36, pp. 1118-1124, doi: 10.1016/j.renene.2010.08. 026.

[43] YESILBUDAK M., SAGIROGLU S., COLAK I. A new approach to very short term wind speed prediction using k-nearest neighbor classification. Energy Convers. Manage. 2013, 69, pp. 77-86, doi: 10.1016/j.enconman.2013.01.033.

[44] JIANG Y., SONG Z., KUSIAK A. Very short-term wind speed forecasting with Bayesian structural break model, Renew. Energ. 2013, 50, pp. 637-647, doi: 10.1016/j.renene. 2012 07.041 .

[45] EFRON B. Missing data imputation and the bootstrap. JASA 1994, 89, pp. 463-475, doi: 10. 2307/2290846

[46] BISHOP C.M. Pattern Recognition and Machine Learning. New York: Springer, 2006.

[47] THEODORIDIS S., KOUTROUmBAS K. Pattern Recognition. San Diego: Academic Press, 2006. 